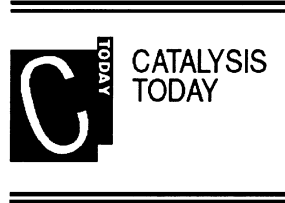

ELSEVIER

Catalysis Today 59 (2000) 61-68

www.elsevier.com/locate/cattod

\title{
Pt and Pd supported on glass fibers as effective combustion catalysts
}

\author{
L. Kiwi-Minsker ${ }^{a}$, I. Yuranov ${ }^{\text {a }}$, E. Slavinskaia ${ }^{\text {b }}$, V. Zaikovskii ${ }^{\mathrm{b}}$, A. Renken ${ }^{\mathrm{a}, *}$ \\ ${ }^{a}$ Institute of Chemical Engineering, Swiss Federal Institute of Technology, CH-1015 Lausanne, Switzerland \\ ${ }^{\mathrm{b}}$ Boreskov Institute of Catalysis, Novosibirsk, Russia
}

\begin{abstract}
Pd and Pt supported on glass fiber materials with developed porosity and high specific surface areas were studied in total propane oxidation. The reaction was carried out in recycling reactor and the kinetic parameters were determined under different reaction conditions in the temperature range $200-500^{\circ} \mathrm{C}$. Pt catalysts were seen to be more active than $\mathrm{Pd}$ for the same metal loading on identical support. Catalytic activity was seen to depend on support composition. The highest activity was observed on Pt supported on glass fiber modified by titania, demonstrating the ignition temperatures around $200^{\circ} \mathrm{C}$. The catalyst surface morphology and surface dispersion of active metal were characterized by high-resolution electron microscopy. (C) 2000 Elsevier Science B.V. All rights reserved.
\end{abstract}

Keywords: Glass fibers; Catalytic activity; Catalytic combustion; Structured catalysis

\section{Introduction}

Catalytic combustion, an alternative to conventional flame combustion, has received considerable attention during the last decades [1]. Application of the catalytic combustion in stationary or mobile systems shows significant advantages in controlling pollutant emissions and the more efficient use of energy sources. This is due to the lower operating temperatures precluding the formation of toxic compounds. The incinerators based on catalytic combustion typically operate at temperatures below $400^{\circ} \mathrm{C}$. GHSV values are in the range $1000-100000 \mathrm{~h}^{-1}$. For economic reasons, the pressure drop in catalytic converters should be as low as possible. Therefore, highly active catalysts are desirable leading to complete oxidation within short residence times.

\footnotetext{
* Corresponding author. Tel.: +41-21-693-3181; fax: +41-21-693-3190.

E-mail address: albert.renken@epfl.ch (A. Renken)
}

The catalysts used for combustion are mainly noble metals supported on pellets, honeycomb ceramic monolith, parallel plates, fiber pads, and gauze or sintered metals. Catalytic fixed-bed reactors are known to have some drawbacks like high pressure drop in the bed, flow maldistribution and susceptibility to fouling by dust. Catalytic incinerators based on structured catalytic beds are considered as a most suitable alternative to the former ones. At present a variety of monolithic honeycombs are used for this purpose. The main drawbacks of monolith reactors in use are their high weight to volume ratio, rather high manufacturing cost and their susceptibility to thermal and mechanical shock.

The structured catalytic materials made from woven glass fibers present an innovative alternative in the design of combustion reactors [2-7]. These materials combine mechanical elasticity and resistance to thermal shock with open regular macrostructure: tissues, gauze, 3D-block and other woven structures can be easily obtained.

Total oxidation of hydrocarbons and carbon monoxide is often used as model for catalytic combustion. 
Recently we reported the results concerning the $\mathrm{CO}$ oxidation at atmospheric pressure over glass fiber (GF) based catalysts [2]. The Pd supported on glass fiber were shown to be very active catalysts in $\mathrm{CO}$ oxidation, but the application was limited by the operation temperature of $400^{\circ} \mathrm{C}$. Above this temperature, porous glass fibers were observed to lose their mechanical strength and to decrease specific surface area.

The present study is aimed on further development of the GF catalysts as combustion catalytic materials in order to enhance their thermal stability and activity through suitable surface modification of the GF supports. Platinum and palladium are known to be the most active noble metals used in catalytic combustion and therefore, they were chosen as active components. Propane oxidation is taken as a model combustion reaction and the detailed kinetics of this reaction over Pd and Pt supported on different glass fibers are reported.

\section{Experimental}

\subsection{Catalyst preparation}

The commercial aluminoborosilicate (E-type) glass fibers (EGF) produced by Vetrotex France S.A. were used in woven form as starting materials for the preparation of the GF supports. The specific surface area (SSA) of the starting glass fiber materials is $\sim 2 \mathrm{~m}^{2} \mathrm{~g}^{-1}$. The fabrics of EGF were pre-treated at $90^{\circ} \mathrm{C}$ in $1.0 \mathrm{~N}$ aqueous solutions of $\mathrm{HCl}$ in order to leach out the non-silica components of glass and to create a porosity in the support. By this procedure the SSA of the material was varied from 2 up to $275 \mathrm{~m}^{2} \mathrm{~g}^{-1}$ depending on pre-treatment conditions employed, like temperature and contact time with the acidic solution. The samples were then rinsed in distilled water and dried in air at $50^{\circ} \mathrm{C}$ overnight.

Also silica glass fibers (SGF), supplied by "Steklovolokno" (Polotsk, Belarus), with chemical composition of $\sim 97 \%$ of $\mathrm{SiO}_{2}$ was used as support. The SSA of these supports could not be enhanced by acidic treatment and they were used as received in woven form without any treatment.

The surface of porous glass fibers was modified by titania (TGF), zirconia (ZGF) and alumina (AGF) to increase the thermostability of the supports. The modification was made by impregnation of the porous glass fibers with aqueous solution of suitable salts and consequent calcination on air.

The supported Pd and Pt catalysts were prepared by ion-exchange or impregnation from aqueous ammonia solutions $(\mathrm{pH}=10)$ of noble metal salts, followed by drying and calcination at $450^{\circ} \mathrm{C}$ in air for $1 \mathrm{~h}$. Palladium(II) chloride $\mathrm{PdCl}_{2}$ and hexachloroplatinic acid $\mathrm{H}_{2} \mathrm{PtCl}_{6}$ (purum, Fluka Chemie AG, Buchs, Switzerland) were used as precursors of the active components. The industrial granulated catalyst CK-306 was used for referencing of catalytic activity. The main characteristics of the catalysts are presented in Table 1.

Table 1

Catalysts tested in propane oxidation

\begin{tabular}{rlllr}
\hline Number & Catalyst & $\begin{array}{l}\text { Surface modifying } \\
\text { component }\end{array}$ & $\begin{array}{l}\text { Content of active compo- } \\
\text { nent, Pd or Pt (wt. })\end{array}$ & $\begin{array}{l}\text { SSA } \\
\left(\mathrm{m}^{2} \mathrm{~g}^{-1}\right)\end{array}$ \\
\hline 1 & $0.2 \mathrm{Pd} / \mathrm{SGF}$ & - & 0.2 & 2 \\
2 & $0.2 \mathrm{Pd} / \mathrm{EGF}$ & - & 0.2 & 15 \\
3 & $0.2 \mathrm{Pd} / \mathrm{AGF}$ & $\mathrm{Al}_{2} \mathrm{O}_{3}$ & 40 \\
4 & $0.1 \mathrm{Pd} / \mathrm{TGF}$ & $\mathrm{TiO}_{2}$ & 56 \\
5 & $0.2 \mathrm{Pd} / \mathrm{TGF}$ & $\mathrm{TiO}_{2}$ & 0.1 & 55 \\
6 & $0.3 \mathrm{Pd} / \mathrm{TGF}$ & $\mathrm{TiO}_{2}$ & 0.2 & 56 \\
7 & $0.2 \mathrm{Pd} / \mathrm{ZGF}$ & $\mathrm{ZrO}_{2}$ & 0.3 & 50 \\
8 & $0.2 \mathrm{Pt} / \mathrm{EGF}$ & $-\mathrm{Al}_{2}$ & 0.2 & 15 \\
9 & $0.2 \mathrm{Pt} / \mathrm{AGF}$ & 0.2 & 40 \\
10 & $0.1 \mathrm{Pt} / \mathrm{TGF}$ & $\mathrm{TiO}_{2}$ & 0.2 & 56 \\
11 & $0.2 \mathrm{Pt} / \mathrm{TGF}$ & $\mathrm{TiO}_{2}$ & 0.1 & 55 \\
12 & $0.3 \mathrm{Pt} / \mathrm{TGF}$ & $\mathrm{TiO}_{2}$ & 0.2 & 56 \\
13 & Industrial catalyst CK-306 & & 0.3 & $11(\mathrm{Cr}), 0.05(\mathrm{Pd})$ \\
\hline
\end{tabular}


The BET surface area (SSA) and pore size distribution (PSD) of the supports and catalysts were measured using $\mathrm{N}_{2}$ adsorption-desorption at $77 \mathrm{~K}$ via a Sorptomatic 1990 (Carlo Erba) instrument. The samples to be analyzed were set in the ampoule in woven form. The SSA of the samples was calculated by employing the BET method, while the Dollimore/Heal method was applied for the calculation of mesopore size distribution.

The investigations of surface morphology were carried out via transmission electron microscopy in a CM-20 electron microscope (accelerating voltage $200 \mathrm{kV}$, lattice resolution $0.2 \mathrm{~nm}$ ). High-resolution HT-2000 electron microscope fitted with field-emission gun (accelerating voltage $200 \mathrm{kV}$, lattice resolution $0.14 \mathrm{~nm}$ ) was also used. The images were recorded by slow scan Gatan CCD camera. Samples for TEM observations were prepared by two methods. Elementary filaments were fixed in the electron microscope sample holder and studied in its initial state. Only the external surface of glass fiber could be investigated in this case. In the second method the samples were mechanically crushed and ethanol suspension of the crushed sample was deposited on holey carbon film fixed on standard copper grid and then dried. Small pieces of glass fibers were investigated in this case.

\subsection{Experimental set-up}

The reactor used for the study of propane oxidation was a continuous flow fixed-bed reactor with an external recycle loop and a membrane compressor [3]. The recycling was never less than 100 . Therefore, the reactor can be considered as an ideal continuous stirred tank reactor.

Rolled up woven GF catalyst (mass about $0.4 \mathrm{~g}$ ) was placed into the reactor. The temperature in the catalytic bed was measured by a sheathed thermocouple.

The gases $\mathrm{C}_{3} \mathrm{H}_{8}$ (10 vol.\% in $\mathrm{Ar}$ ), $\mathrm{O}_{2}$, and $\mathrm{Ar}$ (99.9\%, Carba-Gas, Lausanne, Switzerland) were used without further purification. The total gas feed was $100 \mathrm{ml} \mathrm{min}^{-1}$ (STP) and was monitored through mass flow controllers. The $\mathrm{C}_{3} \mathrm{H}_{8}$ concentration in the feed could be varied from 0.1 to $2.5 \mathrm{vol} . \%$, the $\mathrm{O}_{2}$ concentration was varied from 1 to $30 \mathrm{vol} . \%$ and argon was used as diluent gas. Outlet $\mathrm{C}_{3} \mathrm{H}_{8}, \mathrm{CO}$ and $\mathrm{CO}_{2}$ gas concentrations were continuously monitored by an infrared analyzer Ultramat 22P (Siemens) and measured by GC 8000 (Fisons). Carboxen 1000 column was used for the separation of propane from other gases. It was operated at $225^{\circ} \mathrm{C}$ and the flow rate of carrier gas $(\mathrm{He})$ was $50 \mathrm{ml} \mathrm{min}^{-1}$.

The reaction rate, used as a characteristic of catalytic activity, was calculated as the amount of $\mathrm{C}_{3} \mathrm{H}_{8}$ moles reacted per second per gram of the catalyst, $-R_{\mathrm{p}}\left(\mu \mathrm{mol}_{\mathrm{p}} \mathrm{g}^{-1} \mathrm{~s}^{-1}\right)$. The kinetics of the propane oxidation was treated with a simple empirical power law: $-R_{\mathrm{p}}=k_{0} \exp \left(\Delta E_{\mathrm{a}} / R T\right) C_{\mathrm{p}}{ }^{n} C_{\mathrm{O}_{2}}{ }^{m}$. The partial reaction order, $n$, was derived from data obtained at low propane conversions, usually less than $15 \%$, in big excess of oxygen. The apparent activation energies, $\Delta E_{\mathrm{a}}$, were evaluated from the Arrhenius plots $\left(\ln R_{\mathrm{p}}-1 / T\right)$, for which the $R_{\mathrm{p}}$ values were measured for the same propane concentration in the reactor $\left(C_{\mathrm{p}}\right)$ at different temperatures.

\section{Results and discussion}

\subsection{Propane oxidation over Pd catalysts}

The catalytic activity of Pd supported on different glass fibers was measured at a propane inlet concentration of $0.57 \mathrm{vol} . \%$ in excess of oxygen (10 vol.\%) in the temperature range from 260 up to $500^{\circ} \mathrm{C}$. Un-

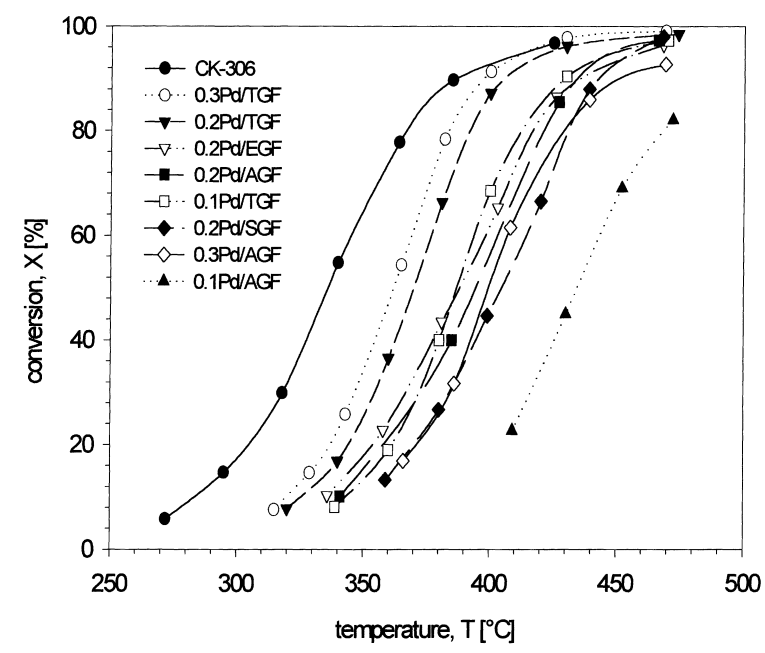

Fig. 1. Propane conversion as a function of temperature (Pd catalysts): $Q=100 \mathrm{ml} \mathrm{min}^{-1}$ (STP); $m_{\text {cat }}=0.414 \mathrm{~g}$; inlet concentrations: 0.5 vol. $\% \mathrm{C}_{3} \mathrm{H}_{8}, 10$ vol. $\% \mathrm{O}_{2}$. 
Table 2

Activity of Pd catalysts in propane oxidation

\begin{tabular}{lllll}
\hline Number & Catalyst & $\begin{array}{l}\text { Temperature } \\
\text { range } \Delta T\left({ }^{\circ} \mathrm{C}\right)\end{array}$ & $\Delta E_{\mathrm{a}}\left(\mathrm{kJ} \mathrm{mol}^{-1}\right)$ & $\begin{array}{l}R_{\mathrm{p}} \text { at } 365^{\circ} \mathrm{C}, C_{\mathrm{p}}=0.3 \mathrm{vol} \% ; \\
C_{\mathrm{O}_{2}}=9 \mathrm{vol}^{\circ} \%\left(\mu \mathrm{mol}_{\mathrm{p}} \mathrm{g}^{-1} \mathrm{~s}^{-1}\right)\end{array}$ \\
\hline 1 & $0.2 \mathrm{Pd} / \mathrm{SGF}$ & $385-425$ & 170.1 & 0.081 \\
2 & $0.2 \mathrm{Pd} / \mathrm{EGF}$ & $360-410$ & 146.6 & 0.179 \\
3 & $0.2 \mathrm{Pd} / \mathrm{AGF}$ & $365-410$ & 122.6 & 0.169 \\
4 & $0.1 \mathrm{Pd} / \mathrm{TGF}$ & $360-400$ & 172.2 & 0.178 \\
5 & $0.2 \mathrm{Pd} / \mathrm{TGF}$ & $340-380$ & 154.6 & 0.447 \\
6 & $0.3 \mathrm{Pd} / \mathrm{TGF}$ & $330-365$ & 146.5 & 0.603 \\
7 & $0.2 \mathrm{Pd} / \mathrm{ZGF}$ & $340-380$ & 106.7 & 0.502 \\
8 & $\mathrm{CK}-306$ & $320-365$ & 115.1 & 1.414 \\
\hline
\end{tabular}

der the reaction conditions the products over all $\mathrm{Pd}$ catalysts studied were $\mathrm{CO}_{2}$ and $\mathrm{H}_{2} \mathrm{O}$. The dependence of propane conversion on the reaction temperature is shown in Fig. 1. The results of catalytic activity at $365^{\circ} \mathrm{C}$ are presented in Table 2. The reaction order with respect to propane concentration was found to be $0.5 \leq n \leq 0.6$.

From the obtained data it is seen that the activity of Pd supported on glass fibers of E-type (EGF) is two times higher than the activity of Pd supported on silica glass fibers (SGFs). Both catalysts (samples 1 and 2) contain the same amount of active phase $(0.2 \mathrm{wt} . \%$ of Pd), but the EGF support has an SSA of $15 \mathrm{~m}^{2} \mathrm{~g}^{-1}$ and the SSA of SGF is $2 \mathrm{~m}^{2} \mathrm{~g}^{-1}$. Moreover, the HREM data revealed that $\mathrm{Pd}$ has a higher dispersion on the EGF surface than on the SGF. This explains the higher catalytic activity of $0.2 \mathrm{Pd} / \mathrm{EGF}$ catalyst per gram than the $0.2 \mathrm{Pd} / \mathrm{SGF}$.

As it was already mentioned in Section 1, the main drawback of the EGF catalysts is the limitation of the operating temperature at $400^{\circ} \mathrm{C}$. Therefore, the EGF supports were modified by different oxides, like $\mathrm{Al}_{2} \mathrm{O}_{3}, \mathrm{TiO}_{2}$ and $\mathrm{ZrO}_{2}$ to increase thermostability and enhance operating temperature. Formation of oxide layers with different chemical and structural properties on the fiber surface strongly influence the catalytic activity. The catalysts with equal Pd loading of $0.2 \%$, supported on TGF and ZGF, are 2.5-3.0 times more active (see Table 2) than Pd on EGF support. Increasing Pd content on TGF support from 0.1 to $0.3 \mathrm{wt} . \%$ leads to the proportional increase in activity. This indicates that the dispersion of Pd remains constant within this concentration range.

\subsection{Propane oxidation over Pt catalysts}

All Pt/GF catalysts tested in propane oxidation demonstrated high activity. $\mathrm{CO}_{2}$ and $\mathrm{H}_{2} \mathrm{O}$ were the only reaction products. The catalytic activity of $\mathrm{Pt}$ catalysts, even at low Pt loading (0.05 wt.\%), was seen to be much higher at temperatures up to $320^{\circ} \mathrm{C}$ than the catalytic activity of industrial catalyst CK-306. The reaction rates of propane oxidation over Pt catalysts at $320^{\circ} \mathrm{C}$ and the activation energies, determined under oxygen excess conditions $(10 \mathrm{vol} . \%)$ at constant concentration of propane $(0.3 \mathrm{vol} . \%)$, are listed

Table 3

Activity of Pt catalysts in propane oxidation

\begin{tabular}{lllcl}
\hline Number & Sample & $\begin{array}{l}\text { Temperature } \\
\text { range } \Delta T\left({ }^{\circ} \mathrm{C}\right)\end{array}$ & $\Delta E_{\mathrm{a}}\left(\mathrm{kJ} \mathrm{mol}^{-1}\right)$ & $\begin{array}{l}R_{\mathrm{p}} \text { at } 320^{\circ} \mathrm{C}, C_{\mathrm{p}}=0.3 \text { vol.\%; } \\
C_{\mathrm{O}_{2}}=9 \mathrm{vol}^{\circ}\left(\mu \mathrm{mol}_{\mathrm{p}} \mathrm{g}^{-1} \mathrm{~s}^{-1}\right)\end{array}$ \\
\hline 1 & $0.2 \mathrm{Pt} / \mathrm{EGF}$ & $310-330$ & 87.4 & 0.51 \\
2 & $0.2 \mathrm{Pt} / \mathrm{AGF}$ & $310-350$ & 95.8 & 0.59 \\
3 & $0.1 \mathrm{Pt} / \mathrm{TGF}$ & $280-320$ & 115.9 & 0.93 \\
4 & $0.2 \mathrm{Pt} / \mathrm{TGF}$ & $280-320$ & 99.5 & 1.78 \\
5 & $0.3 \mathrm{Pt} / \mathrm{TGF}$ & $270-325$ & 95.8 & 1.94 \\
6 & $\mathrm{CK}-306$ & $320-365$ & 115.1 & 0.28 \\
\hline
\end{tabular}


in Table 3. Comparison of the reaction rates allows to examine the support modification and the content of $\mathrm{Pt}$ in relation to catalytic activity. It is seen from Table 3 that the modification of EGF support by $\mathrm{Al}_{2} \mathrm{O}_{3}$ (AGF) does not influence the catalytic activity of Pt catalysts. At the same time modification by $\mathrm{TiO}_{2}$ leads to increase in the catalytic activity: $0.2 \mathrm{Pt} / \mathrm{TGF}$ is 3.5 times more active than $0.2 \mathrm{Pt} / \mathrm{EGF}$. The increase of Pt content from 0.1 to $0.2 \mathrm{wt} . \%$ on this TGF support increases the reaction rate two times. But further increasing Pt content up to $0.3 \mathrm{wt} . \%$ did not change the catalytic activity.

The temperature dependency of propane conversion over Pt/GF catalysts is presented in Fig. 2. The propane conversion was observed to increase slowly with temperature than in the case of $\mathrm{Pd} / \mathrm{GF}$ catalysts, resulting in lower apparent activation energies calculated from the Arrhenius plots.

The kinetics of propane oxidation over Pt/GF catalysts drastically differs from the kinetics over Pd/GF catalysts. The observed reaction order over Pt catalysts was negative with respect to oxygen, indicating reaction inhibition by oxygen. Propane conversion dependency on oxygen concentration is shown in Fig. 3. With increasing oxygen concentration propane conversion drastically goes down. The highest reaction rate is reached for stoichiometric reaction mixture with molar ratio of $\mathrm{C}_{3} \mathrm{H}_{8}: \mathrm{O}_{2}=1: 5$.

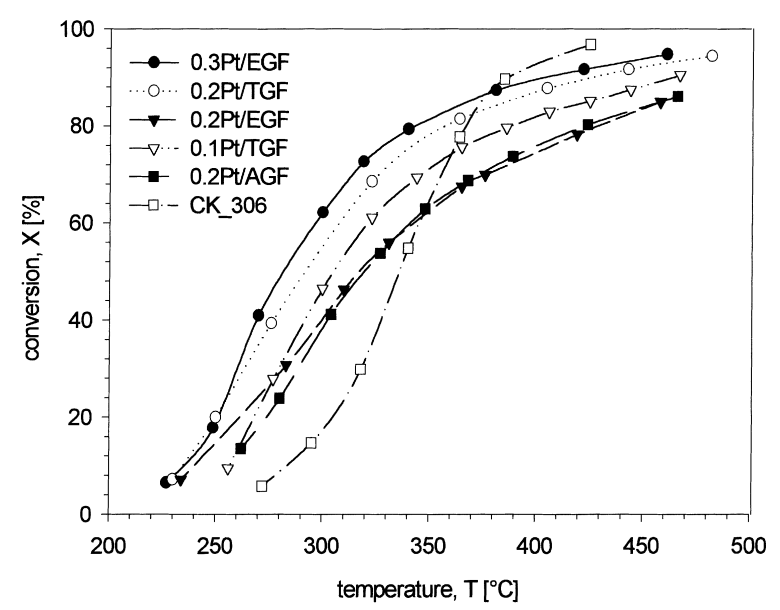

Fig. 2. Propane conversion as a function of temperature (Pt catalysts): $Q=100 \mathrm{ml} \mathrm{min}^{-1}$ (STP), $m_{\text {cat }}=0.414 \mathrm{~g}$; inlet concentrations: 0.5 vol. $\% \mathrm{C}_{3} \mathrm{H}_{8}, 10$ vol. $\% \mathrm{O}_{2}$.

The investigation of partial reaction order with respect to propane was carried out at 30-fold oxygen excess and propane conversion lower than $15 \%$. In this case the change of oxygen concentration was negligible and partial propane order was found to be close to $n=1$ (see Fig. 4). The total reaction order, $(n+m)$, was estimated from experimental kinetics results with stoichiometric reactants mixture of $\mathrm{C}_{3} \mathrm{H}_{8}: \mathrm{O}_{2}=1: 5$. The simulation curves are presented

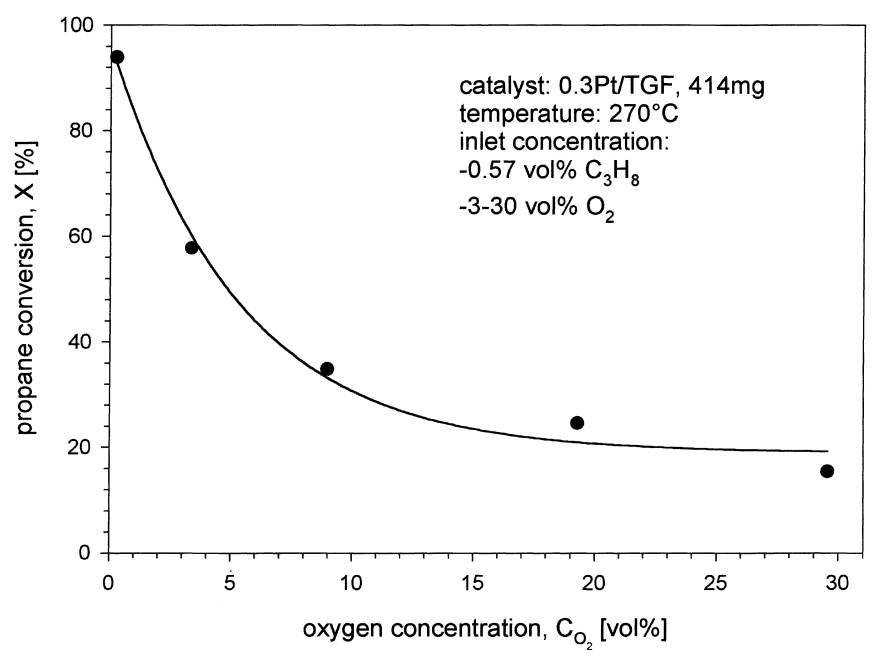

Fig. 3. Propane conversion as a function of oxygen concentration over $0.3 \mathrm{Pt} / \mathrm{TGF}$ catalyst: $m_{\mathrm{cat}}=0.414 \mathrm{~g} ; T=270^{\circ} \mathrm{C}$; inlet concentrations: 0.57 vol. $\% \mathrm{C}_{3} \mathrm{H}_{8}, 3-30$ vol. $\% \mathrm{O}_{2}$. 


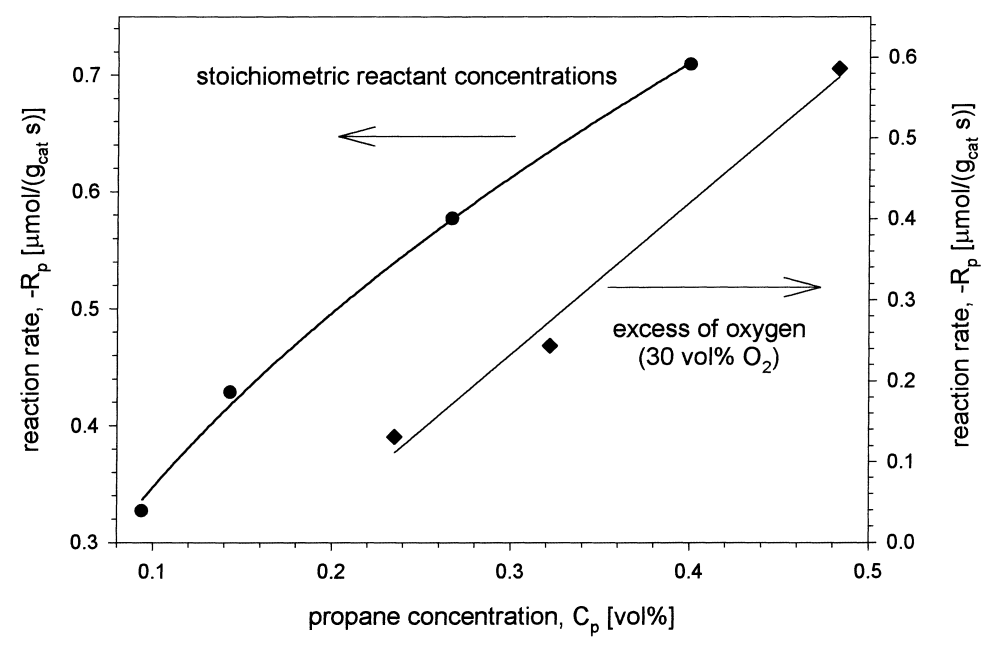

Fig. 4. Measured and calculated transformation rate of propane for stoichiometric reactant concentrations $\left(C_{\mathrm{p}} / C_{\mathrm{O}_{2}}=\frac{1}{5}\right)$ and for high excess of oxygen $(30 \mathrm{vol} . \%)\left(T=232^{\circ} \mathrm{C} ; Q=100 \mathrm{ml} \mathrm{min}^{-1}\right.$ (STP), $\left.0.3 \mathrm{Pt} / \mathrm{TGF} ; m_{\mathrm{cat}}=414 \mathrm{mg}\right)$.

in Fig. 4 with simulation parameters $(n+m)=0.5$, and consequently $m=-0.5$ in correspondence with the reaction inhibition by oxygen.

The temperature dependency of propane conversion at stoichiometric ratio of the reagents and at $\sim 20$-fold excess oxygen is presented in Fig. 5. From this figure it is seen that a $90 \%$ conversion in stoichiometric mixture is reached at $\sim 250^{\circ} \mathrm{C}$, while with 20 -fold excess oxygen the temperature is about $375^{\circ} \mathrm{C}$.
Order with respect to alkane from 1 to 3 was reported for Pt wire [8]. Over Pd wire the alkane oxidation is nearly independent of the oxygen partial pressure. In this case the partial reaction order for alkane was observed to be $n=0.5-0.8$, being in agreement with our findings. The activation energies reported are in the range $70-110 \mathrm{~kJ} \mathrm{~mol}^{-1}$. The decrease in reaction rate with oxygen concentration (inhibition by $\mathrm{O}_{2}$ ) was observed also for supported $\mathrm{Pt} / \mathrm{Al}_{2} \mathrm{O}_{3}$ catalyst [9]. The

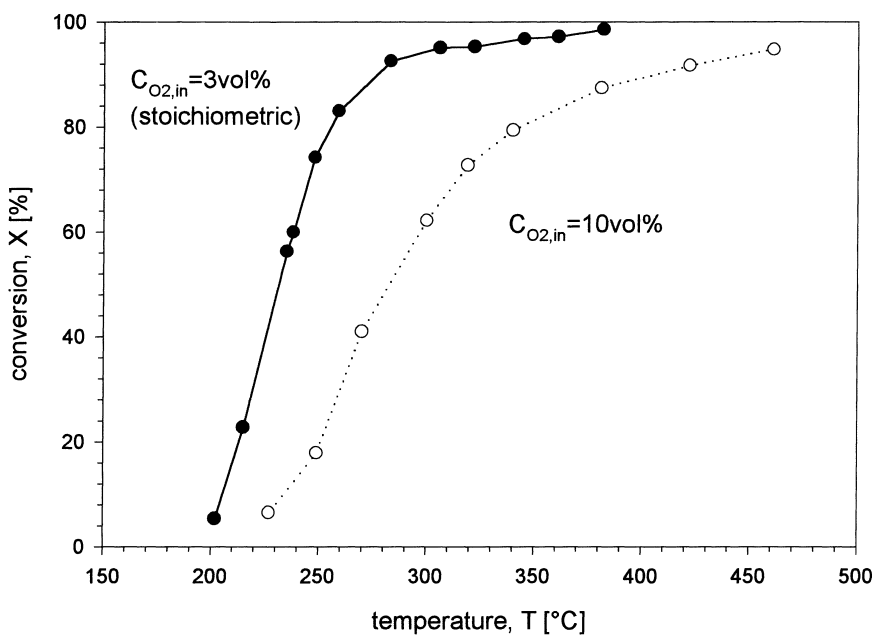

Fig. 5. Propane conversion as a function of temperature for different $\mathrm{O}_{2}$ inlet concentrations: $Q=100 \mathrm{ml} \mathrm{min}^{-1}$ (STP), $0.3 \mathrm{Pt} / \mathrm{TGF}$, $m_{\text {cat }}=0.414 \mathrm{~g}$; inlet concentrations: 0.57 vol. $\% \mathrm{C}_{3} \mathrm{H}_{8}$. 
highest reaction rate was found when alkane to oxygen stoichiometric ratio was used.

The difference in reaction kinetics over $\mathrm{Pd}$ and $\mathrm{Pt}$ catalysts can be explained by different catalytic oxidation mechanisms. The oxygen surface coverage on $\mathrm{Pt}$ is expected to be less than on Pd and dependent on the $\mathrm{O}_{2}$ /hydrocarbon ratio. The adsorption of hydrocarbon over $\mathrm{Pt}$ competes with $\mathrm{O}_{2}$ adsorption, which explains the observed negative oxygen reaction order.

\subsection{Catalyst characterization by electron microscopy}

In order to characterize the morphology of fiber surface and the effect of modification by oxides on the active metal dispersion, TEM and HREM study was carried out. Three samples were examined: $0.2 \mathrm{Pd} / \mathrm{EGF}, 0.2 \mathrm{Pd} / \mathrm{AGF}$ and $0.2 \mathrm{Pd} / \mathrm{TGF}$. The view of outer surface profile of an elementary filament is presented in Fig. 6. The outer surface of EGF and

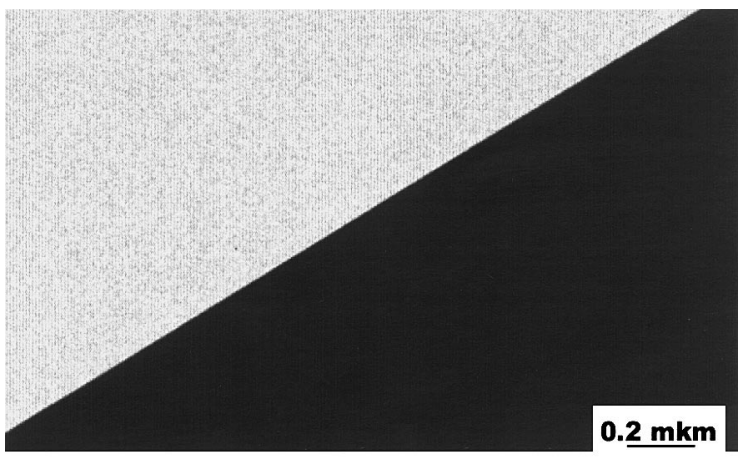

(a)

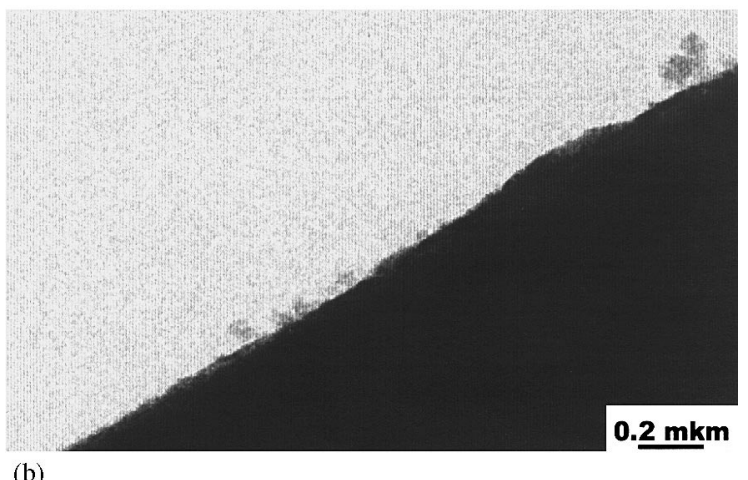

(b)

Fig. 6. Transmission electron micrographs of the elementary filament profiles: (a) AGF fiber; (b) TGF fiber.

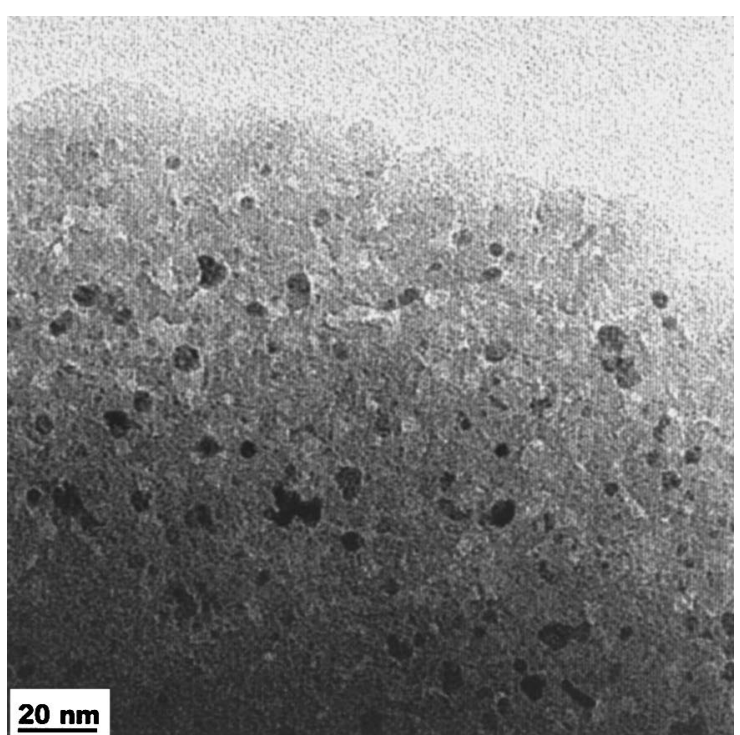

(a)

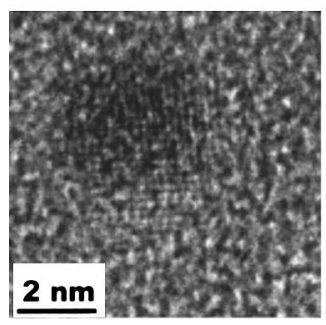

(b)

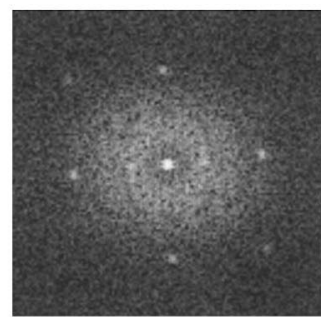

(c)
Fig. 7. Transmission electron micrographs of $0.2 \mathrm{Pd} / \mathrm{AGF}$ catalyst surface: (a) porous structure of AGF support with Pd metal particles; (b, c) HREM micrograph and corresponding Fourier transformed picture of $\mathrm{Pd}$ particle.

AGF fibers was seen to be smooth and without any inhomogenity (Fig. 6a), while some small particles of different forms were visible on the TGF external surface (Fig. 6b). These particles consist of amorphous $\mathrm{TiO}_{2}$ phase with disordered structure of anatase, including small crystallites with a diameter of $2-5 \mathrm{~nm}$. Probably, due to the presence of these particles and their poor adhesion to the glass surface TGF as well as ZGF supports demonstrated partial loss of oxide outer layer under mechanical stress.

The noble metal interaction with the support is known to involve the active metal dispersion, sintering and reduction. In this study we compared $\mathrm{Pd}$ properties of the same content $(0.2 \mathrm{wt} . \%)$ deposited 
on EGF, AGF and TGF supports. From the TEM images a high dispersion of Pd was obtained on all supports under the study. As seen from Fig. 7a the small particles with diameter $10-30 \AA$ predominate, although some bigger particles were also present. The HREM images allowed to obtain the crystallographic parameters of these particles by direct measurements of the lattice spacing (see Fig. 7b). The values of 2.25 and $1.95 \AA$ correspond to ( $\left.\begin{array}{llll}1 & 1 & 1\end{array}\right)$ and $\left(\begin{array}{lll}2 & 0 & 0\end{array}\right)$ crystallographic planes of metallic Pd [10].

The higher catalytic activity of $0.2 \mathrm{Pd} / \mathrm{TGF}$ catalyst relates to its specific surface morphology. Highly dispersed $\mathrm{Pd}$ is located mostly on the $\mathrm{TiO}_{2}$ particles, and not on the surface of the glass, resulting in more active state of $\mathrm{Pd}$ due to interaction with the titania support.

\section{Conclusions}

The following conclusions can be drawn from this work:

- Platinum and palladium supported on different glass fibers with developed porosity and high specific surface areas have been demonstrated as effective combustion catalysts.

- Platinum catalysts are more active than palladium in total propane oxidation, showing ignition temperatures of $200-220^{\circ} \mathrm{C}$.

- Modification of glass fiber support by titania and zirconia leads to an increase in activity, allowing to achieve over the best catalysts propane conversions close to $100 \%$ at short residence times of $\sim 10^{-1} \mathrm{~s}$.

- Mechanical properties of TGF and ZGF have to be further improved in order to avoid a loss of oxide outer layer under mechanical stress, which is usually induced by a high gas velocity in combustion reactor.

- Kinetics of propane total oxidation was studied and reaction orders with respect to propane was found to be $n=0.5$ over Pd catalysts.

- Decrease in the reaction rate with increasing oxygen concentration (reaction inhibition by oxygen) was observed over all Pt catalysts and the reaction order with respect to oxygen was found to be $m=-0.5$ and to propane $n=1$.
- Catalyst characterization by HREM has shown high dispersion of Pt and Pd on glass fiber surfaces.

\section{Nomenclature}

$\begin{array}{ll}R_{\mathrm{p}} & \begin{array}{l}\text { reaction rate }\left(\mu \mathrm{mol}_{\mathrm{p}} \mathrm{g}^{-1} \mathrm{~s}^{-1}\right) \\ m, n\end{array} \\ & \begin{array}{l}\text { partial reaction orders to oxygen and } \\ \text { propane, respectively }\end{array} \\ \mathrm{SSA} & \begin{array}{l}\text { specific surface area }\left(\mathrm{m}^{2} \mathrm{~g}^{-1}\right) \\ m_{\text {cat }}\end{array} \\ Q & \text { catalyst mass }(\mathrm{g}) \\ C & \text { total flow rate }\left(1 \mathrm{~s}^{-1}\right) \\ T & \text { concentration }(\mathrm{vol} . \%) \\ x & \text { temperature }\left({ }^{\circ} \mathrm{C}\right)\end{array}$

\section{Acknowledgements}

The authors gratefully acknowledge the financial support from the Swiss National Science Foundation under the contract No. 7 IP 051298. The authors would also like to thank Prof. Ph. Buffat (CIME EPFL) for fruitful discussions and high expertise in the interpretation of HREM results.

\section{References}

[1] M. Zwinkels, S. Järas, P. Govind Menon, Catal. Rev. Sci. Eng. 35 (3) (1993) 319-358.

[2] Yuranov, L. Kiwi-Minsker, V. Barelko, A. Renken, in: G.F. Froment, K.C. Waugh (Eds.), Reaction Kinetics and the Development of Catalytic Processes, 1999, Elsevier Amsterdam, pp. 191-198.

[3] L. Kiwi-Minsker, I. Yuranov, B. Siebenhaar, A. Renken, Catal. Today, submitted for publication.

[4] D.M. Nicholas, Y.T. Shah, I.A. Zlochower, Ind. Chem. Prod. Res. Dev. 15 (1) (1976) 29-35, 35-41.

[5] A. Kalantar Neyestanaki, L.-E. Lindfors, Combust. Sci. Technol. 97 (1994) 121-136.

[6] A. Kalantar Neyestanaki, L.-E. Lindfors, Combust. Sci. Technol. 110-111 (1995) 303-320.

[7] D.L. Trimm, C.W. Lam, Chem. Eng. Sci. 35 (1980) 1405-1413, 1731-1739.

[8] Yung-Fang Yu Yao, Ind. Eng. Chem. Prod. Res. Dev. 19 (1980) 293-298.

[9] C. Hoang-Van, R. Harivolona, S. Fayeulle, Catalysis and automotive pollution control III, Stud. Surf. Sci. Catal. 96 (1995) 249-259.

[10] X-ray powder data file, Set 46, Nos. 1043 and 1107, JCPDF International Center for Diffraction Data, PA, USA, 1996. 